\title{
Salespeople Stress and How Should They Cope With It To Avoid the Burnout
}

\author{
Rajesh Srivastava
}

PhD, Associate Professor of Marketing, Department of Marketing, Middle Tennessee State University, USA

\begin{abstract}
This paper develops a theoretical model that focuses on the extent to which coping may reduce boundaryspanning employee burnout. Based on data collected from 512 salespeople in the US, I conclude that those sales people that use right form of coping will end up reducing burnout. Burnout is known to cause a negative impact on a company, so if the determinants are realized then managers and employees can one day learn to effectively cope and maybe even prevent this dangerous cancer from spreading throughout the organization. My model reveals that coping has a major influence in reducing burnout in sales people. A great way to deal with these negative outcomes of sales job is to cope with the stress on a regular basis. Salespeople who take the positive approach or also called problem focused approach tend to deal with the stress in much better form; they attack the root cause of it and tend to have less effect of emotional exhaustion and depersonalization. While those who take the negative approach or emotion focused approach, tend to show a negative effect of stress and display higher incidence of exhaustion and depersonalization. Employees of the companies and especially managers need to be educated on these topics so that when problems arise they will be prepared to handle them in a manner that will maximize the organization's productivity and reduce stress. If the problems is caught and tackled early on, then employees would not have to spend their time and energy on negatively coping with these stressful situations. The employees should be taught to cope with stress in a positive manner and should be taught to take problem-focused approach to coping.
\end{abstract}

Keywords: burnout, boundary spanner, coping, depersonalization, emotional exhaustion, sales people, stress.

JEL Classification: M.

(C) The Author, 2018. This article is published with open access at Sumy State University.

\section{Introduction}

Stress has always been a factor-affecting employee at work. It has always been a major contributing factor to high turnover and absenteeism around the world. Stress affects not only the health of employees but also their productivity at work (Ichniowski, Shaw \& Rennushi, 1997). WHO estimates that it will cost businesses up to $\$ 300$ billion a year (Smith, 2012). The World Health Organization (WHO) called stress the "Health epidemic of the 21st century". Three out of every four employees describe their work as stressful (Stewart et al., 2003).

In 1974, Herbert Freudenberger, a clinical psychologist who studied staff members of "alternative" institutions and their responses to stress, introduced the term burnout (Jackson et al., 1986). According to Webster's Dictionary, burnout is defined as the exhaustion from long-term stress. Researchers use Maslach's definition of burnout, which divides burnout into three components: emotional exhaustion, depersonalization, and feelings of low personal accomplishment (Maslach, 1982). Researchers agree that emotional exhaustion is at the heart of, or in other words, the first stage of the burnout process, so much so that research focuses on determining the dimensions of exhaustion and their relationship to the burnout phenomenon (Cordes and Dougherty, 1993; Gaines and Jermier, 1983). Boundary spanning employees constantly work under stress and constraints of the internal and the external environment (Bettencourt and Brown, 2003; Goolsby, 1992; Pruden and Reese, 1972; Lewin and Sager, 2007). High levels of stress lead to not only lower levels of work performance, satisfaction, organizational commitment, innovation, and creativity but also higher levels of withdrawal, absenteeism and turnover. (Kroon, van de Voorde \& van Veldhoven, 2009; Sardžoska and Tang, 2015; Srivastava and Tang, 2015).

Burnout is an important concept to study because it can lead to understanding and, in some cases, preventing high turnover rates, depressed and unsatisfied employees, poor performance, and other such internal inefficiencies. If the determinants of burnout can be realized, the managers will be better equipped to handle and prevent the destructive consequences of burned-out employees. 
The study of burnout is especially important in the United States because the U.S. is the most overworked country in the industrialized world, even surpassing Japan. The overload of work in the U.S. can be blamed on fewer number of vacation days, increasing employee layoffs, and low levels of staff to do high levels of work (Ammondson, 2001). Berglas, a clinical psychologist and former columnist for Inc. Magazine, argues that "U.S. society's glorification of material wealth" can be to blame for the rise of burnout (Goeters, 2001). The U.S. is filled with workaholics who attempt to take on larger workloads at the expense of their emotional and physical health, which also increases the chance for burnout to occur (Ramsey, 2002).

It is necessary to the success of an organization for the employees, especially supervisors, to be aware of the symptoms of burnout. Numerous physical symptoms are caused by burnout such as physical depletion; frequent colds; head, neck and backaches; gastrointestinal disorders; and sleeping disorders. Emotional symptoms can also overwhelm a victim of burnout. Examples of these emotional symptoms include helplessness, depression, failure, anger and frustration, and hopelessness (Stanley, 2001). Being aware of these symptoms will aid in the proper treatment of burnout so that an organization can operate effectively and efficiently.

\section{Burnout}

For many years burnout was an untouched topic. According to Cordes and Dougherty, it was not until the late 1970s and early 1980s that systematic empirical studies on burnout were conducted and published (1993). Although there are many areas of burnout to cover in the future, it is important to note significant studies in the past.

As stated previously, the most widely accepted explanation of burnout is Maslach's three dimensions of burnout: emotional exhaustion, depersonalization, and reduced personal accomplishment (Maslach and Jackson, 1981). Emotional exhaustion occurs in highly demanding, people-oriented situations where a lack of energy is felt and one can go no more mentally or physically (Babakus, 1999). Depersonalization occurs when workers are treated as objects rather than human beings. A reduced sense of personal accomplishment, the third dimension of Maslach's burnout model, is experienced by individuals who do not feel they have job competence of successful achievement when it comes to their ability to deal with people (Cordes and Dougherty, 1993). Raymond Lee and Blake Ashforth have worked together to research the meaning of Maslach's three dimensions of burnout. Their article, "On the Meaning of Maslach's Three Dimensions of Burnout," provides support for Maslach's model where emotional exhaustion and depersonalization were highly correlated (1990). Lee and Ashforth's 1996 article attempts to provide an understanding of how different correlates associate with the three different components. Emotional exhaustion was more strongly linked to the demand and resource correlates than were depersonalization or personal accomplishment. Also, the demand correlates had a stronger link with emotional exhaustion than did the resource correlates.

Since emotional exhaustion has such importance to the burnout model, it has been the focus of various researchers. Examinations of the relationships between emotional exhaustion, attitudes, and behavior in the selling environment have been the focus of such research. The results of these examinations have proved the significance of the burnout construct in the research of salespeople. They have also explained the negative impact that emotional exhaustion has on job satisfaction and organizational commitment. Studying this further could reduce salespeople's intentions to leave an organization (Babakus et al., 1999; Lewin and Sager, 2008; Kemp et al., 2013).

Emotional exhaustion has also been researched in high stress organizations, such as police organizations. Results suggest that "emotional exhaustion is partially the result of personal characteristics of the employee, interpersonal milieu, and the work itself, but is profoundly affected by departmental context, administrative policy and practices, and the contradictory mandate of police on society" (Gaines and Jermier, 1983).

Evidence has shown that intention to leave may be a result of job stress and that job satisfaction of salespeople is intertwined with their role perceptions and job stress (Sager, 1994; Lewin and Sager, 2008). Along with these findings, role stress among industrial buyers needs to be determined so that a successful selling environment can occur (Michaels et al., 1987). It can be noted here that role stress and burnout should not be used interchangeably. There is conceptual and etiological distinction between the two (Singh et al., 1994).

Our study indicates the relationships between coping, emotional exhaustion, withdrawal in a sales environment. The results, which support previous findings, indicate that "role conflict is significantly related to emotional exhaustion; work-family conflict is significantly related to both emotional exhaustion and job satisfaction; and that emotional exhaustion and job satisfaction are related to a sales person's propensity to leave" 
(Boles et al., 1997). This study combined many aspects of previous research together to determine the relationship between the variables.

The manner in which people cope with burnout has also been a subject of numerous past studies. Coping, defined by Webster's Dictionary, means to struggle to overcome problems or difficulties. Studying coping and developing models that will help to explain coping proves to be pertinent to the study of burnout. If a model is developed that determines what managers could do to affect the relationship between coping and burnout, then a proactive approach to avoid stressed-out and exhausted employees. Employee attitudes, job performance, and longevity are just a few things that could be improved by researching burnout and coping.

Folkman and Lazarus are $(1985 ; 1986)$ two researchers who have done a significant amount of research on coping. Their samples have included adults, undergraduate students, and married couples to name a few. One of their studies was to determine influential factors of the coping process and any consistencies people use to cope with different stressful events. In all the diverse stressful situations, they found that both problem- and emotion-focused coping were used (Folkman and Lazarus, 1980). In their study of married couples, situations appraised as changeable by subjects were dealt with by using more confrontive coping, playful problem-solving, and positive reappraisal, where as situations viewed as having to be accepted by subjects were dealt with by using more distancing and escape-avoidance (Folkman, et al., 1986). Problem focused coping involves activities that deliberately removes the stress causing activities. This includes tactics aimed at deliberate efforts to remove all causes of stress (Lazarus and Folkman, 1980; 1985; Srivastava and Sager, 1999; Lewin and Sager, 2008; Srivastava and Tang, 2015).

\section{Coping}

As mentioned earlier, it is important to study coping and its relationship to burnout. Leiter, in his research with staff members of a hospital, found that people with large amounts of coping resources will experience less burnout (1990). He also researched staff members of mental hospitals to determine what coping strategies contribute to the development of burnout. His findings showed that escapist-coping was compatible with burnout, whereas control-coping was incompatible with burnout (Leiter, 1991). Stress, a factor in burnout, is more effectively alleviated when a combination of suppression and direct coping, which are potentially adaptive strategies of managing stress, is used (Parkes, 1990). Aldwin and Revenson found that the more people use emotional-focused coping, the more likely there will be problems in the future due to an increase in emotional distress (1987). An example of a problem in the future is burnout.

Studies have been done on certain professional fields. Keaveney and Nelson researched a random sample of retailers and found the retailers cope by using an intrinsic motivational orientation towards their job. In the human services arena, avoidance strategies are shown not to benefit workers and control-coping strategies do benefit workers by allowing them to deal with a difficult and challenging workload (Koeske, et al., 1993). Salespeople who are optimistic will most likely use problem-focused coping while salespeople who are pessimistic will most likely use emotion-focused coping (Strutton and Lumpkin, 1993). Salespeople perform better in sales presentations because they use problem-focused coping as opposed to those who use emotion-focused coping (Strutton and Lumpkin, 1994). Personality also plays a part in how salespeople cope with sales stress. Those who are more involved, self-determined, and adaptable to change are more likely to use problem-focused coping. Emotion-focused coping is more likely used by those who are alienated and see change as a threat (Strutton, et al., 1995). Srivastava and Sager also studied salespeople using four personal variables: locus of control, task- based self-efficiency, continuance commitment, and social support. A more internal locus of control and greater self-efficiency belief is held by those who use problem-focused coping. Of the four personal characteristics, none were predictive of salespeople's use of emotion-focused coping (1999).

On the basis of the conceptual development, the following research hypothesis can be developed (as represented in Figure 1):

$\mathrm{H}_{1}$ : $\quad$ Problem-focused copers will experience less emotional exhaustion than Emotion-focused copers.

$\mathrm{H}_{2}$ : $\quad$ Problem-focused copers will experience less depersonalization than Emotion-focused copers. 


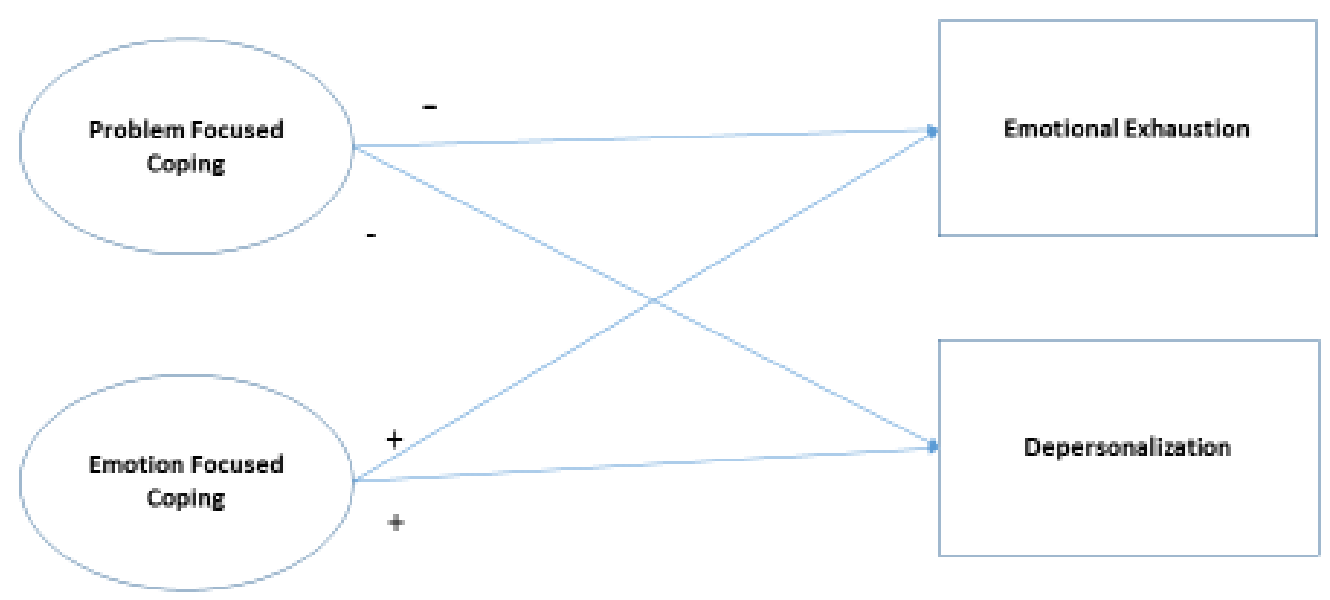

Figure 1. Influence of coping style on outcome variables

\section{Methodology}

\section{Sample}

Salespersons from the domestic US sales force of an international manufacturer of specialty chemical products were selected. This organization employed 1,200 salespeople and 100 sales managers arrayed into several geographic divisions. Twenty-five percent of salespeople were females, although females represent about 40 percent of new hires.

A 10-page self-administered questionnaire was mailed to all 1,200 salespeople's home address. We obtained responses from 918 salespeople (return rate $=76.5 \%$ ). For the present study, the actual sample size was 512, due to our specific variables selected for our theoretical model.

\section{Measure}

We used two burnout constructs as our outcome variables - 8 items were used in depersonalization and 8 items were used in reduced accomplishment (Singh, Goolsby, \& Rhoads, 1994). We selected, problem-focused coping and emotion-focused coping, from Ways of Coping Checklist (Folkman and Lazarus, 1980, 1985). A 5point Likert type frequency response format was used with the following scale anchors: strongly disagree (1) to strongly agree (5). The reliabilities (Cronbach's alpha) are provided in Table 1.

\section{Results}

\section{Descriptive:}

Table 1 and Table 2 shows the mean, standard deviation, Cronbach's alpha, and correlations of all variables at the sub-construct level. The Cronbach alpha reliability is .75 or more except for emotional exhaustion. Table 2 shows that Regression value of coping strategies and the burnout variables.

\section{Measurement model:}

Our model provided excellent results. The problem focused coping was negatively related to emotional exhaustion (-.13) and depersonalization (-.36) while emotion focused coping was positively related to emotional exhaustion (.20) and depersonalization (.12). All these beta values were significant at $\mathrm{p}<.05$ level. Overall $\mathrm{F}$ value was also significant at $\mathrm{p}<.05$ level. This support hypothesis 1 and 2 (See Figure 2). The variance inflation factor is over 1 in each case. The Durbin Watson is over 2 in each case. The p value is significant at .00 level. 


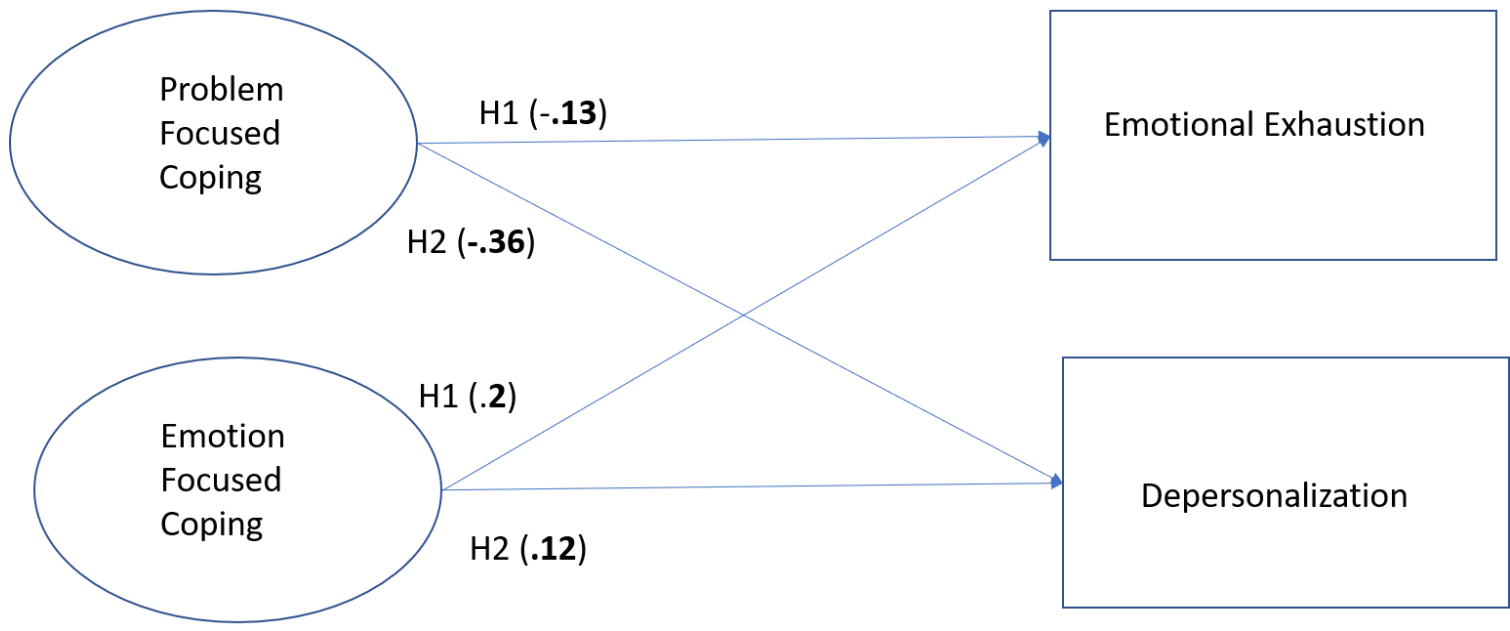

Figure 2. Influence of coping style on outcome variables: Hypothesis 1 and 2

Table 1. Descriptive statistics and correlations

\begin{tabular}{|c|l|c|c|c|c|c|c|c|}
\hline \multicolumn{1}{|c|}{ Variables } & $\mathrm{M}$ & $\mathrm{SD}$ & Alpha & 1 & 2 & 3 & 4 \\
\hline 1 & Problem focused coping & 3.69 & .54 & .78 & - & $-.25^{* *}$ & $-.42^{* *}$ & $-.29 * *$ \\
\hline 2 & Emotion focused coping & 1.99 & .60 & .66 & & - & $.20^{* *}$ & $.23^{* *}$ \\
\hline 3 & Depersonalization & 2.11 & .60 & .88 & & & - & $.41^{* *}$ \\
\hline 4 & Emotional exhaustion & 1.99 & .74 & .80 & & & & - \\
\hline
\end{tabular}

Notes: ** Correlation is significant at .01 level ( 2 tailed)

Table 2. Models predicting coping style

\begin{tabular}{|l|c|c|c|c|c|c|}
\hline \multirow{2}{*}{ Outcome variables } & \multicolumn{2}{|c|}{ Problem focused coping } & \multicolumn{3}{|c|}{ Emotion focused coping } \\
\cline { 2 - 6 } & Beta & $\mathrm{P} \leq$ & VIF & beta & $\mathrm{P} \leq$ & $\mathrm{VIF}$ \\
\hline Emotional exhaustion & -.13 & .00 & 1.20 & .20 & .00 & 1.20 \\
\hline Depersonalization & -.36 & .00 & 1.20 & .12 & .01 & 1.20 \\
\hline & \multicolumn{2}{|c|}{$\begin{array}{c}\mathrm{F}=55.79 \mathrm{p} \leq .000 \\
\text { Adjusted } \mathrm{R}^{2}=.20 \\
\text { Durbin Watson=2.12 }\end{array}$} & $\begin{array}{c}\mathrm{F}=18.40 \mathrm{p} \leq 000 \\
\text { Adjusted } \mathrm{R}^{2}=.07 \\
\text { Durbin Watson=2.03 }\end{array}$ \\
\hline
\end{tabular}

\section{Conclusion}

It is imperative to organizations that the determinants of burnout are discovered in order to prevent any negative impacts that burnout might cause to the organization. The focus of many of the past studies that were previously mentioned was to analyze the concept of burnout and its consequences in order to be able to come up with a solution to the problem. Burnout is known to cause a negative impact on a company, so if the determinants are realized then managers and employees can one day learn to effectively cope and maybe even prevent this dangerous cancer from spreading throughout the organization.

Research has shown that burnout has many negative results for both the organization and the individual. For example, dysfunctional ramifications of burnout can include increased turnover, absenteeism, reduced productivity, and human considerations (Jackson \& Maslach, 1982; Leiter \& Maslach, 1988; Shirom, 1989). Managers need to have a clear understanding of the burnout construct so that these ramifications can be avoided or successfully coped with.

The consequences of burnout can be grouped into five categories: physical emotional, interpersonal, attitudinal, and behavioral (Kahill, 1988). The physical and emotional consequences have been linked to various mental and physical health problems. The interpersonal consequences of burnout have affected relationships that employees have with their family and friends (Jackson \& Maslach, 1982). The attitudinal consequences of burnout have caused bad attitudes towards clients, the job, the organization, or oneself (Kahill, 1988). Behavioral consequences include both organizational behaviors as well as consumption behaviors. Examples of behavioral consequences are turnover (Jackson et al., 1986), absenteeism (Firth \& Britton, 1989), and 
decreases in both quality and quantity of an employee's job performance (Maslach \& Jackson, 1985). Two examples of consumption behaviors that burnout may cause are smoking and drug and alcohol abuse (Cordes and Dougherty, 1993).

One way to deal with these negative outcomes of sales job is to cope with the stress on a regular basis. Salespeople who take the problem focused approach tend to deal with the stress in much better form and tend to show less effect of emotional exhaustion and depersonalization. While those who take the emotion focused approach, tend to show a negative effect of stress and display higher incidence of exhaustion and depersonalization.

From all of the research done, it is safe to say that managers need be very aware of all aspects of burnout, and all of the consequences that come as a result of each. Managers need to be educated on these topics so that when problems arise they will be prepared to handle them in a manner that will maximize the organization's morale and productivity. If the problems can be caught and extinguished early on, then employees would not have to spend their time and energy on negatively coping with these stressful situations. The employees should be taught to cope with stress in a positive manner and should be taught to take problem focused approach to coping.

\section{References}

1. Aldwin, C. and Revenson T. (1987). Does Coping Help? A Reexamination of the Relation between Coping and Mental Health. Journal of Personality and Social Psychology, 53, 337-348.

2. Ammondson, P. (2001). "Beat Job Burnout." $T+D, 55,68-70$.

3. Babakus, E., Cravens D., Johnston M., and Moncrief W. (1999). The Role of Emotional Exhaustion in Sales Force Attitude and Behavior Relationships. Journal of the Academy of Marketing Science, 27, 58-70.

4. Boles, J., Johnston M., and Hair, J. (1997). Role Stress Work-Family Conflict and Emotional Exhaustion: Inter-Relationships and Effects on Some Work Related Consequences. Journal of Personal Selling \& Sales Management, 20, 17-28.

5. Cordes, C.L. and Dougherty T. (1993). A Review of an Integration of Research on Job Burnout. Academy of Management Review, 18, 621-656.

6. Firth, H. and Britton P. (1989). Burnout, Absence, and Turnover Amongst British Nursing Staff. Journal of Occupational Psychology, 62, 55-59.

7. Folkman, S. and Lazarus R. (1980). An Analysis of Coping in a Middle-Aged Community Sample. Journal of Health and Social Behavior, 21, 219-239.

8. Folkman, S. and Lazarus R. (1985). If It Changes It Must Be a Process; A Study of Emotion and Coping During Three Stages of a College Examination. Journal of Personality and Social Psychology, 48, 150-170.

9. Folkman, S. and Lazarus R., Dunkel-Schetter C., DeLongis A., and Gruen R. (1986). Dynamics of a Stressful Encounter: Cognitive Appraisal, Coping and Encounter Outcomes. Journal of Personality and Social Psychology, 50, 992-1003.

10. Gaines, J. and Jermier J. (1983). Emotional Exhaustion in a High Stress Organization. Academy of Management Journal, 26, 567-586.

11. Goeters, E. (2001). Reclaiming the Fire: How Successful People Overcome Burnout. Library Journal, $126,118$.

12. Goolsby, J. (1992). A Theory of Role Stress in Boundary Spanning Positions of Marketing Organizations. Journal of the Academy of Marketing Science, 20, 155-164.

13. Ivancevich, J.M. and Matteson, M.T. (1986). Organizational level stress management interventions: A review and recommendations. Journal of Organizational Behavior Management, 8, 229-248.

14. Jackson, S.E. and Maslach C. (1982). Burnout: A Concept in Need of Refinement. Paper presented at the annual meeting of the American Psychological Association, Washington, D.C.

15. Jackson, S.E., Schwab R. and Maslach C. (1986). Toward an Understanding of the Burnout Phenomenon. Journal of Applied Psychology, 71, 630-640.

16. Kahill, S. (1988). Symptoms of Professional Burnout: A Review of the Empirical Evidence. Canadian Psychology, 29, 284-297.

17. Kemp, E., Aberdeen, L. B. and Ricks, J. M. (2013). Sales manager support: fostering emotional health in salespeople. European Journal of Marketing, 47, 635-654.

18. Koeske, G. F., Kirk S., and Koeske R. (1993). A Panel Study of Coping with Involuntary Job Loss. Academy of Management Journal, 66, 319-335. 
19. Kroon, B., van de Voorde, K., \& van Veldhoven, M. (2009). Cross-level effects of high-performance work practices on burnout: Two counteracting mediating mechanisms compared, Personnel Review, 38, 509-525.

20. Lee, Raymond T. and Ashforth B. (1996). A Meta-Analytic Examination of the Correlates of the Three Dimensions of Job Burnout. Journal of Applied Psychology, 81, 123-133.

21. Leiter, M. (1990). The Impact of Family Resources, Control Coping, and Skill Utilization on the Development of Burnout: A Longitudinal Study. Human Relations, 43, 1067-1083.

22. Leiter, M. (1991). Coping Patterns as Predictors of Burnout: The Function of Control and Escapist Coping Patterns. Journal of Organizational Behavior, 12, 123-144.

23. Leiter, M. and Maslach C. (1988). The Impact of Interpersonal Environment on Burnout and Organization Commitment. Journal of Organizational Behavior, 9, 297-308.

24. Lewin, J. E., and Sager, J. K. (2008). Salespeople burnout: A test of the coping-meditational model of social support. Journal of Personal Selling \& Sales Management, 28, 233-239.

25. Maslach, C. (1982). Understanding Burnout: Definitional Issues in Analyzing a Complex Phenomenon. In Job Stress and Burnout: Research, Theory, and Intervention Perspectives. Ed. Whiton Steward Pine. Beverly Hills, CA: Sage, 29-40.

26. Maslach, C. and Jackson S. (1981). The Measurement of Experienced Burnout. Journal of Occupational Behavior, 2, 99-113.

27. Michaels, Ronald E., Ralph L. Day, and Erich A. Joachimsthaler (1987). Role Stress Among Industrial Buyers: An Integrative Model. Journal of Marketing 51 (April): 28-45.

28. Parkes, K. (1990). Coping, Negative Affectivity, and the Work Environment: Additive and Interactive Predictors of Mental Health. Journal of Applied Psychology, 75, 399-409.

29. Pruden, H. O., and Reese, R. (1972). Inter-organization role-set relation and the performance and satisfaction of industrial salesmen. Administrative Science Quarterly, 17,601-609.

30. Ramsey, R. D. (2002). A Word to Workaholics. Supervision, 63, 6-8.

31. Sager, J. K. (1994). A Structural Model Depicting Salespeople's Job Stress. Journal of the Academy of Marketing Science, 22, 74-84.

32. Sardžoska, E. G. and Tang, T. L. P. (2015). Monetary Intelligence: Money attitudes - unethical intentions, intrinsic and extrinsic job satisfaction, and coping strategies in Macedonia. Journal of Business Ethics, 130, 93-115.

33. Shirom, A. (1989). Burnout in Work Organizations. In C.L. Cooper and I. Robertson (Eds.). International Review of Industrial and Organizational Psychology, 25-48. New York: Wiley.

34. Singh, J., Goolsby J., and Rhodes G. (1994). Behavioral and Psychological Consequences of Boundary Spanning Burnout for Customer Service Representatives. Journal of Marketing Research, 20, 84-91.

35. Smith, N. (2012). Employees reveal how stress affects their jobs. Business News Daily, 1-4.

36. Srivastava, R. and Tang, T. L. P. (2015). Coping intelligence: Coping strategies and organizational commitment among boundary spanning employees. Journal of Business Ethics, 130, 525-542.

37. Stanley, T.L. (2001). Burnout: A Manager's Worst Nightmare. Supervision 62, 3-5.

38. Stewart, W. F., Ricci, J. A., Chee, E., Hahn, S. R., \& Morganstein, D. (2003). Cost of lost productive work time among US workers with depression. Journal of the American Medical Association, 289, 3135-3144.

39. Strutton, D. and Lumpkin J. (1993). The Relationship Between Optimism and Coping Styles of Salespeople. Journal of Personal Selling and Sales Management, 13, 71-82.

40. Strutton, D. and Lumpkin J. (1994). Problem- and Emotion-Focused Coping Dimensions and Sales Presentation Effectiveness. Journal of the Academy of Marketing Science, 22, 28-37.

41. Strutton, D, Pelton L., and Lumpkin J. (1995). Personality Characteristic and Salespeople's Choice of Coping Strategies. Journal of the Academy of Marketing Science, 23, 132-140.

42. Srivastava, R. and Sager J. (1999). Influence of Personal Characteristics on Salespeople's Coping Style. The Journal of Personal Selling \& Sales Management, 19, 47-58.

43. Srivastava, R. and Tang, T. L. P. (2015). Coping intelligence: Coping strategies and organizational commitment among boundary spanning employees. Journal of Business Ethics, 130, 525-542.

44. Webster's Desk Dictionary of the English Language (1990). New York: Random House, Inc. 